\title{
CILOSTAZOL DID NOT INDUCE ANY ADVERSE REACTIONS IN CORONARY ARTERIAL DISEASE (NON-ST ELEVATION MYOCARDIAL INFARCTION) WITH CONGESTIVE HEART FAILURE COMORBIDITY: A CASE REPORT
}

\author{
YEDY PURWANDI SUKMAWAN* \\ Department of Clinical Pharmacy, Program Study of Pharmacy, Institute of Health Science Bakti Tunas Husada, \\ Tasikmalaya, Indonesia. Email: yedipur@gmail.com
}

Received: 16 August 2016, Revised and Accepted: 06 October 2016

\begin{abstract}
The study to monitor the adverse reactions related to cilostazol used in coronary arterial disease with congestive heart failure comorbidity. This case report describes monitored 63-year-old males with dyspnea that had recently begun using cilostazol after switched from aspirin caused by asthma related to aspirin. After 10 days monitored for adverse reactions of cilostazol used, revealed there was no adverse reaction to be related to cilostazol and the patient came home with improvement. Cilostazol did not show any adverse reactions in this report. However, more data and longterm monitoring will needed. In addition, biologic variations may influence. Therefore, need to determine which population do not affect the harm of cilostazol.
\end{abstract}

Keywords: Dyspnea, Cilostazol, Monitoring.

(C) 2017 The Authors. Published by Innovare Academic Sciences Pvt Ltd. This is an open access article under the CC BY license (http://creativecommons. org/licenses/by/4. 0/) DOI: http://dx.doi.org/10.22159/ajpcr.2017.v10i1.14721

\section{INTRODUCTION}

Cardiovascular has been the leading cause of death in the world. NonST elevated myocardial infarct is formed of coronary arterial disease that constitutes the most common cause of cardiovascular death. In the absence of contraindications, all patient with non-ST elevated should be treated in the emergency department with intranasal oxygen (if oxygen saturation is low), aspirin, clopidogrel, sublingual nitroglycerin, oral $\beta$-blockers, and an anticoagulant (unfractionated heparin, enoxaparin, fondaparinux, or bivalirudin) [1]. Moreover, in another clinical trials experiment showed the combination of aspirin, clopidogrel, and cilostazol reduced of thrombotic complication in the primary and secondary prevention of heart attacks. In addition, this triple antiplatelet reduced long-term cardiac and cerebral events after percutaneous coronary intervention (PCI) [2]. Cilostazol is a phospodiesterase III inhibitor (PDE III inhibitor) that has been approved by the FDA in 1999, the therapeutic target focus on cyclic adenosine monophosphate with the main effect is inhibited platelet aggregation (thrombosis), and dilation of the arteries contributes to supply blood to the legs [3-6]. Nevertheless, cilostazol contraindicated in patients with congestive heart failure and associated with increased mortality and adverse reactions such as cardiac arrhythmia, palpitation, tachycardia, and edema [3,7]. However, another PDE III inhibitors such as amrinone and milrinone are used in the treatment of heart failure [8]. Therefore, need closely monitored of cilostazole use in coronary arterial disease with heart failure comorbidity.

\section{CASE REPORT}

In July 2016, a 63-year-old male presented to the hospital with dyspnea. 14 days before, he had experienced dyspnea and felt worse in 3 days ago. The patient had a history of well-controlled hypertension, post$\mathrm{PCI}$, and he was on anticoagulant therapy.

On the physical examination, the arterial blood pressure was 203/91, the heart rate was $109 \mathrm{mmHg}$, and the respiratory rate was $34 /$ minute. Electrocardiography showed normal sinus rhythm, possible left atrial enlargement, inferior infarct, lateral ischemia. Echocardiography revealed an ejection fraction of $28 \%$. Computed tomography scan showed acute infarct cerebral and did not appear any hemorrhage.

Laboratory study revealed an activated partial thromboplastin time 23.2. Other test results were: hemoglobin - $10.4 \mathrm{~g} / \mathrm{dL}$; leukocyte - $7.100 / \mathrm{mm}^{3}$; thrombocyte - $287.000 / \mathrm{mm}^{3}$; hematocryte - 33\%; troponin - I $0.04 \mathrm{ng} / \mathrm{ml}$; creatinine - 10.9; sodium - $138 \mathrm{mmol} / \mathrm{L}$; potassium - $6.1 \mathrm{mmol} / \mathrm{L}$; chloride - $111 \mathrm{mmol} / \mathrm{L}$, casual plasma glucose - $253 \mathrm{mg} / \mathrm{dL}$; $\mathrm{pH}-7.15$.

The patient was diagnosed with non-ST elevated miocardiac infarct, hypertension, hypertension heart disease, congestive heart failure FC III-IV, chronic kidney disease, Type 2 diabetes mellitus, stroke, and the ejection fraction is $28 \%$. At the time of his admission, his medications included farsorbid ( $2.5 \mathrm{mg} / \mathrm{h}$ ), furosemide $(5 \mathrm{mg} / \mathrm{h}$ ), atorvastatin (once daily), lactulose (once daily), pantoprazole $40 \mathrm{mg}$ intravenous (once daily), alprazolam (once daily), insulin 15 I.U. on dextrose $40 \%$, calcium gluconas $4 \mathrm{~g}$ on dextrose $5 \%$, losartan $50 \mathrm{mg}$ (once daily $25 \mathrm{mg}$ ), calcium polystyrene sulfonate (TID), clopidogrel $75 \mathrm{mg}$ (once daily if blood pressure $<160 \mathrm{mmHg}$ ), aspirin $80 \mathrm{mg}$ (once daily blood pressure $<160 \mathrm{mmHg}$ ), and citcholine (BID $250 \mathrm{mg}$ ).

In the $2^{\text {nd }}$ day, calcium gluconas $4 \mathrm{~g}$ on dextrose $5 \%$ was stopped. In the $3^{\text {rd }}$ day aspilet switched to cilostazole (BID $50 \mathrm{mg}$ ), losartan suspended and gave an additional drug of sodium bicarbonate (TID $500 \mathrm{mg}$ ). In the $4^{\text {th }}$ day, gave an additional ketocid (TID). In the $5^{\text {th }}$ day, calcium polystyrene sulfonate (TID) was insulin 15 I.U. on dextrose $40 \%$ was stopped and gave an addition of insulin garglin 12 I.U. (once daily). In the $6^{\text {th }}$ day, losartan was used again and gave an addition combination of salbutamol nebulizer and budesonide nebulizer. On the $8^{\text {th }}$ day was gave an additional of amlodipine $5 \mathrm{mg}$ (once daily). In the $9^{\text {th }}$ day, furosemide was switched to hydrochlorothiazide $12.5 \mathrm{mg}$ (once daily) and was gave an addition of insulin aspart (TID 8 i.u.).

On the last physical examination, before the patient came home, the arterial blood pressure was $162 / 84 \mathrm{mmHg}$, the heart rate was $79 \mathrm{mmHg}$, and the respiratory rate was 17 times per minute. Electrocardiography 
showed normal sinus rhytm, possible left atrial enlargement, and inferior infarct. The symptoms of dyspnea were disappeared.

Laboratory study revealed an activated partial thromboplastin time is 40.3 . Other test results were: Creatinine - 9.6; sodium - $138 \mathrm{mmol} / \mathrm{L}$; potassium - $3.6 \mathrm{mmol} / \mathrm{L}$, and chloride - $108 \mathrm{mmol} / \mathrm{L}$, casual plasma glucose - $126 \mathrm{mg} / \mathrm{dL}$.

Until 12 days hospitalizations and 10 days consumed of cilostazol, there was not showed any adverse reactions. The patient came home with improvement.

\section{DISCUSSION}

In this present case reported switched of aspirin to cilostazol in the $3^{\text {rd }}$ day caused there were contraindication for asthma-related aspirin and 10 days consumed of cilostazol were not showed any adverse reactions that to be related of cilostazol. In addition, the dyspnea was disappeared, and there were not any symptoms felt of patient.

Although the FDA publishes warning about cilostazol contraindicated with patients heart failure of any severity and several drugs with this pharmacologic effect, have caused decreased survival compared to placebo in patients with Class III-IV heart failure [9]. However, the same group of cilostazol like amrinone and milrinone is used in the treatment of heart failure [8]. In a study, comparing the effect of cilostazol and milrinone caused similar increases in cyclic adenosine monophospate (cAMP) levels in human and rabbit platelets [10]. Inhibition of PDE III increase cAMP level cause dilation of smooth muscle, inhibition of platelet aggregation, contraction and increase heart rate, may this function improve the activity of the impair heart and blood circulation simultaneously. Therefore, need to determine which population do not affect the harm of cilostazol.

\section{CONCLUSION}

Cilostazol did not show any adverse reactions in this report. However, more data and long-term monitoring will needed. In addition, biologic variations may influence. Therefore, need to determine which population do not affect the harm of cilostazol.

\section{ACKNOWLEDGMENT}

The author would like to thank Dr. Fanny Abdullah., Sp.JP., M.Kes for endorsement of the research.

\section{REFERENCES}

1. Dipiro JT, Talbert RL, Yee GC, Matzke GR, Wells BG, Posey LM. Pharmacotherapy, A Patophysiologic Approach. New York: Mc Graw Hill; 2008.

2. Han Y, Li Y, Wang S, Jing Q, Wang Z, Wang D, et al. Cilostazol in addition to aspirin and clopidogrel imporves long-term outcomes after percuteneous coronary intervention with acute coronary syndrome: A randomized controled study. Am Heart J 2009; 157(4):733-9.

3. Approval of New Drug Application for Pletal (Cilostazol). Letter to Otsuka American Pharmaceutical, Inc., from Center for Drug Evaluation and Research, Food and Drug Administration, Department of Health \& Human Services; Rockville, MD, January 15, 1999. Available from: http://www.fda.gov/cder/news/cilostazol/20863appletter.htm.

4. Katzung BG, Masters SB, Trevor AJ. Basic and Clinical Pharmacology. New York: McGraw Hill; 2012.

5. Gamssari F, Mahmood H, Ho JS, Villareal RP, Liu B, Rasekh A, et al. Rapid ventricular tachycardias associated with cilostazol use. Tex Heart Inst J 2002;29(2z):140-2.

6. Setyopranoto I, Wibowo S, Tjandrawinata RR. Hemostasis profile and clinical outcome of acute ischemic stroke patients treated with oral lumbrokinase DLBS1033: A comparative study versus aspirin and clopidogrel. Asian J Pharm Clin Res 2016;9(1):186-92.

7. Sweetman SC, editor. Martindale the Complete Drugs Reference. London: Pharmaceutical Press; 2009.

8. Kelley RA, Smith TW. Pharmacological treatment of heart failure. In: Hardman JG, Limbird LE, editors. Goodman \& Gilman's the Pharmacological Basis of Therapeutics. $9^{\text {th }}$ ed. New York: McGrawHill; 1996. p. 809-38.

9. "Cilostazol" July 6, 2016. Available from: https://www.drugs. com>cdi $>$ cilostazol.html. [Last retrieved on 2016 Jul 20].

10. Cone J, Wang S, Tandon N, Fong M, Sun B, Sakurai K, et al. Comparison of the effects of cilostazol and milrinone on intracellular cAMP levels and cellular function in platelets and cardiac cells. J Cardiovasc Pharmacol 1999;34(4):497-504. 